demand) and lowers them in the north and west. They thereby reduce the regional disparities among the non-standardised rates.

For all conditions the adjusted bed rates vary from 3 I 2 for Trent and East Anglia RHAs to 432 for NW Thames, an order of magnitude that is unsurprising and uncontroversial, but for individual groups of conditions extreme variations, $25 \%$ above or below the national mean, are identified for infective and parasitic diseases, and for diseases of the blood and blood-forming organs, respiratory conditions, congenital anomalies, perinatal conditions and the residual category of 'symptoms and ill-defined conditions'.

Haynes concludes the paper with a careful and extended discussion of the implications of his findings. His view is that acute in-patient services will continue to dominate the health service. Not even the most charitable observer would claim that the RHAs with low bed rates for certain conditions have been deliberately anticipating future priorities, or that the present large and arbitrary variations from region to region facilitate the adoption of national priorities. In general terms, the results uphold the redistribution of resources recommended by RAWP but the London and Oxford Regions are not always the most generously endowed with beds, nor the northern and western RHAs always relatively deprived: it depends upon the diagnostic condition. The excessively large regional anomalies imply substantial inequity and require a policy response.

King's College, London

\title{
Glinical Psychology
}

\section{Jeffrey Garland}

Molinari, Victor and Reichlin, Robert E., Life review reminiscence in the elderly: a review of the literature. International Journal of Aging and Human Development, 20 ( 1985 ), $8 \mathrm{I}-92$.

The 84-year-old woman was a 'thick file' patient: a veteran whose 25 year history of psychiatric treatment had left a bulging wad of case notes as her only inheritance. Understandably, the notes gave her dark side, a story of gloom, punctuated by temporary remissions.

She told me to go away. She wanted to die. Nothing could be done: If I didn't believe her, I could 'look at the notes'. I explained that I had done this, but the notes were incomplete. Because of this I would have to ask some important questions. For example: 'When was the last time you were happy?' 
She had never been happy. The notes would make that clear. It was ridiculous even to talk of such a thing.

However, as we went back slowly through her life, reviewing its events, we reached a moment of happiness.

When she was io her parents, pleased on a Saturday night with a good week's takings in their Cardiff corner shop, gave her sixpence, unimaginable riches, to spend at the chippy.

With a friend - 'she had a squint and she smelled, but she was my friend' - she ate fish and chips under a street light in the rain. And they were happy.

This confession, a crack in the Model $\mathrm{T}$ proposition that depressives cling to (you can have any colour you like, as long as it's black), led to another. Yes, the day of her marriage had been... a good day. People had admired her outfit; she'd made it herself.

We made progress from this point, in further sessions leading up to her discharge from hospital. There were a number of therapeutic factors at work for the patient during her stay, and it is not possible to say to what extent life review in itself contributed to her improvement.

As Molinari and Reichlin point out, such anecdotal accounts are all too common in description of life review. We need to move on, to greater coordination between clinical activity and research investigation, and a number of issues should be addressed.

Demographic data on life review reminiscence, as distinct from casual recall of the past, or informative reminiscence for education and retirement, needs to be gathered.

The process of life review needs to be clarified. It is not peculiar to the aged or universal among the elderly; and factors determining its onset or influencing its course remain to be determined.

The elements of reminiscence need to be further explored, and differences in its manifestation between the elderly in the community and old people in institutions need to be better appreciated.

Longitudinal studies of the effects of life review on long-term morale and adjustment are required.

These reminders are timely. As Woods and Britton ${ }^{1}$ point out, reminiscence in a variety of forms is a popular idea with old people and those working with them.

Guidelines for selective use of the different forms of reminiscence are fragmentary at present, and based largely on intuition.

Woods and Britton expect to see the evaluation of reminiscence in all its aspects mushroom over the next few years, and hope it will benefit from the literature on reality orientation.

I would suggest prospective researchers would do better to study the 
gaps in the RO literature, in particular the repeated failure to define clearly what is being studied.

Rightly, Molinari and Reichlin's valuable paper keeps pointing us to the target of understanding the nature of life review, a core component in many therapeutic approaches and likely to be of particular significance for old people.

Oxford District Health Authority

\section{NOTE}

1 Woods, R. T. and Britton, P. G. Clinical Psychology with the Elderly. Croom Helm, London, 1985 . 